\title{
Screening of Potent Arsenic Resistant and Plant Growth Promoting Bacillus species from the Soil of Terai Region of Nepal
}

\author{
Pramod Poudel ${ }^{1,2 *}$, Ashish Nepal ${ }^{1}$, Rashmi Roka Magar ${ }^{1}$, Pratibha Rauniyar ${ }^{1}$, Lil Buda Magar ${ }^{1}$ \\ ${ }^{1}$ Department of Microbiology, National College (NIST), Affiliated to Tribhuvan University, Khushibu, \\ Kathmandu, Nepal, \\ ${ }^{2}$ Research Division, University Grants Commission, Sanothimi, Bhaktapur, Nepal
}

*Corresponding author: Pramod Poudel, Research Division, University Grants Commission, Sanothimi, Bhaktapur, Nepal, Email: poudel.pm@gmail.com

\section{ABSTRACT}

Objectives: To isolate arsenic resistant Bacillus spp. and to determine plant growth promoting activities.

Methods: Eighteen soil samples were collected from the agricultural soil of Terai region of Nepal. Selective isolation of Bacillus species was done by heating the soil at $80{ }^{\circ} \mathrm{C}$ for 15 minutes before the isolation. Nutrient agar was used as an isolation medium. Screening of arsenic resistant Bacillus species was done using nutrient agar supplemented with $100 \mathrm{ppm}$ sodium arsenate and sodium arsenite. For plant growth promoting activity; IAA production was detected taking $0.1 \%$ tryptophane and measuring absorbance at $540 \mathrm{~nm}, \mathrm{NH}_{3}$ production was tested by Nessler's reagent and phosphate solubilization activity was detected by growing colonies on Pikovskaya's agar. Sugar assimilation test was performed to identify the isolates. Most potent arsenic resistant isolate was identified by $16 \mathrm{~S}$ rRNA gene sequencing.

Results: Among 54 randomly selected isolates, 42 were found to be Gram-positive rod-shaped, spore-forming while 12 isolates were Gram-negative bacteria. The isolates $\operatorname{IN}_{1} 2 a_{1} M_{1} 2 a$ and BG $_{3} 4 a$ showed growth on 100 ppm sodium arsenite containing NA. Only isolate $M_{1} 2 a$ tolerated up to 1000 ppm and 15000 ppm of sodium arsenite and sodium arsenate respectively, while other isolates could not grow above $400 \mathrm{ppm}$ sodium arsenite. The isolates $\mathrm{IN}_{1} 2 \mathrm{a}$ and $\mathrm{M}_{1} 2 \mathrm{a}$ were able to produce IAA and solubilize phosphate while $\mathrm{BG}_{3} 4 \mathrm{a}$ could not. Both the isolates $\mathrm{IN}_{1} 2 \mathrm{a}$ and $\mathrm{M}_{1} 2 \mathrm{a}$ were able to utilize the sugars glucose, fructose, lactose, sucrose, galactose, mannose, mannitol, maltose and xylose. Based on the 16S rRNA gene sequencing, isolate $\mathrm{M}_{1} 2 \mathrm{a}$ was identified to be Bacillus flexus with highest similarity of $99.2 \%$.

Conclusion: Arsenic resistant and plant growth promoting Bacillus spp. was isolated from the agricultural soil of Terai region of Nepal.

Key words: Soil, Arsenic resistant Bacillus, Plant growth promotion, Bioremediation

\section{INTRODUCTION}

Arsenic (As) is a poisonous heavy metalloid present in the soil as well as in the water as arsine (III), elemental arsenic (0), arsenite (III) and arsenate (V). It has been reported that, arsenite and arsenate forms are poisonous to environment as well as human health (Dey et al. 2016). The activity that leads to As pollution

Date of Submission: October 22, 2019

Published Online: December, 2019 are mining, smelting, ore processing, and utilization of arsenic-based pesticides or herbicides, and arsenic contaminated water when irrigated posed heavy contamination of soil, especially in cultivated land ecosystem (Shagol et al. 2014). Arsenic consumption beyond a threshold level i.e. 0.05 ppm pose a serious health risk to humans (Dey et al. 2016). Exposure

Date of Acceptance: November 25, 2019

DOI: https:// doi.org/10.3126/tujm.v6i0.26572 
of arsenic to body parts cause cancer. nervous and cardiovascular problems (Ghosh et al. 2011), weight loss, loss of appetite, weakness, lethargy and easily fatigued limits the physical activities and working capacities, chronic respiratory disorder, gastrointestinal disorders like anorexia, nausea, pain in abdomen, enlarged liver and spleen as well as anemia (Dey et al. 2016).

In Nepal, safe drinking water supply is one of the major issues. Groundwater is the foremost source of drinking water in Terai region of Nepal which is usually contaminated with arsenic (Shakya, et al. 2012). Such groundwater when irrigated in crop land increases the concentration of As in crop fields and soil get contaminated. It leads to severe threats for bio amplification by entering into the food chain (Mallick et al. 2014). According to Nepal standard and World Health Organization (WHO) the concentration of arsenic in drinking water are $50 \mu \mathrm{g} / \mathrm{L}$ and $10 \mu \mathrm{g} / \mathrm{L}$ respectively. Nawalparasi district is placed as a prone to the Arsenic problem where the arsenic concentration is significantly beyond the safe limit (Smith et al. 2009).

Moreover, the presence of Arsenic and its forms in the environment has developed a many bacteria Arsenic resistance mechanisms like arsenite methylation, arsenite oxidation, etc. (Mallick et al. 2014). Currently the detoxification of arsenic by using bacteria has become an interest due to environmental issues immersed by other conventional chemical processes (Banerjee et al. 2013). Bacteria play a significant role in the biochemical cycle of arsenic and changes to different oxidation states with different solubility, mobility and toxicity (Banerjee et al. 2013). The important enzyme i.e. arsenic oxidase is present in the protoplasm of arsenic oxidizing bacteria which oxidizes arsenite to arsenate (Dey et al. 2016). Some bacteria such as Bacillus subtilis, Deinococcus indicus, Pseudomonas fluorescens, Thermus aquaticus, Thermus thermophilus, Yersinia enterocolitica, Bacillus arsenicus have efficiently removed soluble and particulate forms of metals, especially from dilute solutions via bioaccumulation (Pepi et al. 2011).

Bacillus species are becoming interest due to its role in wide variety of fields such as bioremediation, enzyme production, plant-growth-promoting (PGP) traits, organic acid production etc. (Poudel et al. 2016). Till now, there are limited research findings on Arsenic resistant and plant growth promoting Bacillus species regardless of their tremendous applications in Nepal.
The main propose of this study is to explore the arsenic resistant Bacillus species having plant growth promoting traits so as to minimize Arsenic pollution and increase the yield of crops. Furthermore, potent Bacillus strains could be applicable as a bio fertilizer for sustainable bioremediation in agriculture.

\section{MATERIALS AND METHODS}

Sample collection, isolation and screening of arsenic resistant bacterial species

Twenty soil samples were collected from Terai region of Nepal. About $20 \mathrm{~g}$ of soil samples was collected in a polythene bag and processed for isolation. For the selective growth of spore forming Bacillus species, $10 \mathrm{~g}$ of soil sample was mixed with $100 \mathrm{~mL}$ of $0.85 \%$ saline solution and placed in $80^{\circ} \mathrm{C}$ water bath for 10 minutes (Travers et al. 1987). It was serially diluted and spread on to nutrient agar plates. All the plates were incubated at $37^{\circ} \mathrm{C}$ for $48 \mathrm{~h}$. Bacterial colonies were sub-cultured onto Nutrient Agar plates supplemented with different concentration of sodium arsenite (up to $800 \mathrm{ppm}$ ) and incubated. The media plates, after incubation, were observed for growth of bacteria colonies. The colonies that showed growth were sub-cultured on nutrient media and incubated. After incubation, these colonies were subjected to further tests and studies (Selvi et al. 2014). Silver nitrate test was performed in NA plates supplemented with sodium arsenite. A single line streak (perpendicular) of the screened organism was drawn on the agar surface and incubated at $37^{\circ} \mathrm{C}$ for $48 \mathrm{~h}$. After incubation, the plates were flooded with 0.1 $\mathrm{M}$ silver nitrate solution and observed for brownish precipitate (Simeonova et al. 2004).

\section{Phenotypic characterization of arsenic-resistant bacteria \\ The bacterial isolates that tolerated arsenate and arsenite concentration were selected and characterized by the morphological and biochemical features (Indole production, MR-VP test, Citrate utilization, Oxidase test, Catalase test, Starch hydrolysis, Gelatin hydrolysis, Triple sugar iron test, Mannitol salt agar, Urea hydrolysis test, Dextrose, Sucrose, Maltose, Rhamnose, Arabinose and Sorbitol tests).}

\section{Effect of arsenic on bacterial growth}

Growth of arsenic resistant bacterial strains was determined in NB medium. From an overnight pure culture, $1 \%$ inoculum was added to $50 \mathrm{ml}$ of $\mathrm{NB}$ medium supplemented with 200 ppm, 400 ppm, 600 
ppm, 800ppm, 1000 ppm sodium arsenite. The cultures were incubated at $37{ }^{\circ} \mathrm{C}$ in an orbital shaker at 120 rpm for $72 \mathrm{~h}$. The growth of the isolate was monitored by measuring optical density at OD $600 \mathrm{~nm}$ using spectrophotometric method.

Effect of $\mathrm{NaCl}$ and $\mathrm{pH}$ in the growth of arsenic resistant isolates

The freshly prepared culture was inoculated into the $5 \mathrm{~mL}$ of sterile $\mathrm{NB}$ and incubated at $37^{\circ} \mathrm{C}$ for $24 \mathrm{~h}$. The optical density of the culture broth was measured at $600 \mathrm{~nm}$ using spectrophotometric method. The $\mathrm{pH}$ of the broth was maintained by using $1 \mathrm{~N} \mathrm{NaOH}$ and $1 \mathrm{~N}$ $\mathrm{HCl}$. The $\mathrm{NaCl}$ concentration in the broth ranged from $1-8 \%$

Determination of plant growth promoting (PGP) activities

The Arsenic resistant Bacillus species were tested for PGP activities based on whether the isolates is capable to solubilize phosphates, produce indole acetic acid, siderophores and $\mathrm{NH}_{3}$. Phosphate solubilization activity was examined by growing isolates in modified Pikovskaya's medium with $0.5 \%$ of tricalcium phosphate (TCP) and incubated at $30^{\circ} \mathrm{C}$ for 5 days. Quantitative analysis of IAA was performed using the method of Loper et al. (1985) at different concentrations of tryptophan $(0,50,150,300,400$ and $500 \mathrm{mg} /$ $\mathrm{ml})$. Isolates were grown for $48 \mathrm{~h}$ on their respective media at $37^{\circ} \mathrm{C}$. Fully-grown cultures were centrifuged at $3000 \mathrm{rpm}$ for $30 \mathrm{~min}$. The supernatant $(2 \mathrm{ml})$ was mixed with two drops of orthophosphoric acid and 4 $\mathrm{ml}$ of the Salkowski reagent $(50 \mathrm{ml}, 35 \%$ of per chloric acid, $1 \mathrm{ml} 0.5 \mathrm{M} \mathrm{FeCl}_{3}$ solution). Development of pink color indicated IAA production. For the ammonia production, freshly grown cultures were inoculated in $10 \mathrm{ml}$ peptone water in each tube and incubated for $48-72 \mathrm{~h}$ at $28^{\circ} \mathrm{C}$. Nessler's reagent $(0.5 \mathrm{ml})$ was added in each tube. Development of brown to yellow color indicated a positive test for ammonia production.

\section{Molecular identification of potent arsenic resistant}

\section{Bacillus species}

Genomic DNA was extracted by using phenolchloroform assay method. DNA Amplification of the 16S rRNA gene was performed using the following universal primer sets: 8f (5' AGA GTT TGA TCC CTC AG 3') and 1492r (5' GGT TAC CTT GTT ACG ACTT $\left.3^{\prime}\right)$. The amplification conditions were as follows: 30 cycles of DNA denaturation at $98^{\circ} \mathrm{C}$ for $10 \mathrm{~s}$, primer annealing at $55^{\circ} \mathrm{C}$ for $5 \mathrm{~s}$, and elongation at $72^{\circ} \mathrm{C}$ for 1 min. Polymerase chain reaction products was purified using the QIAquick PCR Purification Kit according to the manufacturer's instructions. Sequence homology was compared with 16S rRNA gene sequences available in the DDBJ/EMBL/GenBank DNA database using the FASTA algorithm (http://www.ddbj.nig.ac.jp/), and all reference sequences was obtained through the Ribosomal Database Project II (http://rdp.cme. msu.edu/). Sequences were aligned using CLUSTAL W ver.2.01 (http://clustalw.ddbj.nig.ac.jp/) and phylogenetic tree was constructed using MEGA ver.7 by neighbor-joining method with bootstrap values calculated from 1,000 replications.

\section{RESULTS}

In total, 54 colonies were randomly selected and subcultured on NA media. Among this, 42 isolates were Gram positive rods and 12 isolates were Gram negative. Twelve isolates were excluded for further studies. Forty-two isolates showed moist, flat, irregular, and slightly convex colonies on Nutrient agar and were endospore forming rods (Table 1). Among these, 6 isolates had terminal spores, 14 had sub-terminal, and central spore was seen in 22 isolates. Bacillus spp. were isolated from soil having $\mathrm{pH}$ ranging from 5.2-6.3.

Table 1: Position of endospores in bacterial isolates

\begin{tabular}{|c|c|c|c|c|c|}
\hline \multirow{2}{*}{ Location } & \multirow{2}{*}{$\mathrm{pH}$ of soil } & \multirow{2}{*}{ Total no. of isolates } & \multicolumn{3}{|c|}{ Endospore position } \\
\hline & & & Terminal & Sub-terminal & Central \\
\hline Sarlahi & 5.6 & 3 & 1 & 2 & - \\
\hline Biratnagar & 5.9 & 4 & 1 & 3 & - \\
\hline Saptari & 6.1 & 9 & - & 1 & 8 \\
\hline Palpa & 6.3 & 11 & 2 & 5 & 4 \\
\hline Parsa & 5.3 & 2 & 1 & - & 1 \\
\hline Bara & 5.8 & 2 & - & - & 2 \\
\hline Yangjakot & 5.7 & 2 & - & 1 & 1 \\
\hline Birgunj & 5.2 & 5 & 1 & - & 4 \\
\hline Nawalparasi & 6.0 & 4 & - & 2 & 2 \\
\hline
\end{tabular}


In total, only three isolates were able to resist 100 ppm and 1500 ppm of sodium arsenite and sodium arsenate respectively. These isolates were subjected to biochemical tests (Table 2).

Table 2: Biochemical tests of bacterial isolates

\begin{tabular}{|c|c|c|c|}
\hline \multirow{2}{*}{ Test } & \multicolumn{3}{|c|}{ Isolate } \\
\hline & $\mathrm{IN}_{1} 2 \mathrm{a}$ & $M_{1} 2 a$ & $\mathrm{BG}_{3} 4 \mathrm{a}$ \\
\hline Catalase & Negative & Negative & Negative \\
\hline Oxidase & Positive & Positive & Positive \\
\hline $\mathrm{O} / \mathrm{F}$ & Fermentative & Fermentative & Fermentative \\
\hline Indole & Negative & Negative & Negative \\
\hline$M R$ & Positive & Positive & Positive \\
\hline VP & Negative & Negative & Negative \\
\hline Citrate & Negative & Negative & Negative \\
\hline Urease & Negative & Negative & Negative \\
\hline TSIA & Acid/Acid & Acid/Acid & Acid/Acid \\
\hline Motility & Motile & Motile & Motile \\
\hline $\mathrm{H}_{2} \mathrm{~S}$ & Negative & Negative & Negative \\
\hline
\end{tabular}

Two isolates $\mathrm{M}_{1} 2 \mathrm{a}$ and $\mathrm{IN}_{1} 2 \mathrm{a}$ were able to oxidize arsenite to arsenate whereas isolate $\mathrm{BG}_{3} 4$ a was not able to do so (Figure 1). So, BG34a was not tested for PGP activities.

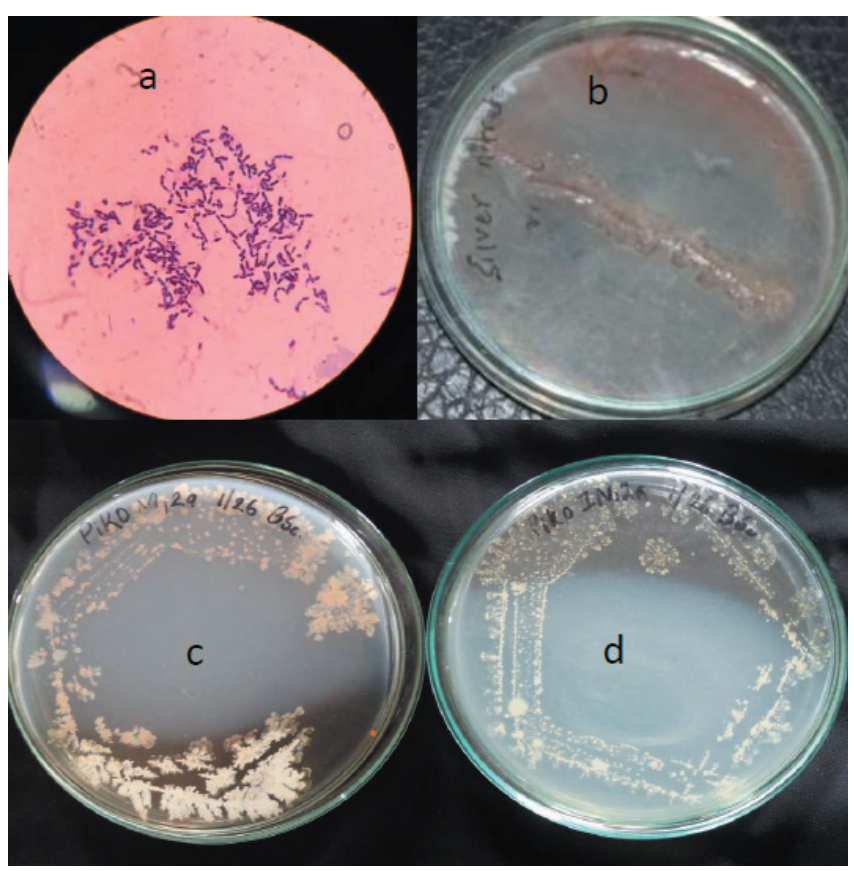

Figure 1: Typical features of Isolates; Gram stain of isolate $M_{1} 2 a(a)$, Detoxifiction of arsenite to arsenate by isolate $M_{1} 2 a(b)$, Phosphate solubilization activity of isolates $M_{1} 2 a(c)$ and $I_{1} 2 a(d)$.

Table 3 describes the IAA production by isolates $\mathrm{IN}_{1} 2 \mathrm{a}$ and $\mathrm{M}_{1} 2 \mathrm{a}$. Maximum absorbance of 0.105 was observed in $\mathrm{IN}_{1}$ 2a culture broth containing tryptophan at $0.05 \mathrm{~g} / \mathrm{L}$ and the lowest value of -0.015 was seen at concentration of $0.22 \mathrm{~g} / \mathrm{L}$. In Isolate $\mathrm{M}_{1} 2 \mathrm{a}$, absorbance of 0.423 was observed at $0.5 \mathrm{~g} / \mathrm{L}$ of tryptophan and lowest of -0.02 at $0.25 \mathrm{~g} / \mathrm{L}$ of tryptophan. 
Table 3: IAA production ability of the isolates after $24 \mathrm{~h}$ of incubation at $37^{\circ} \mathrm{C}$

\begin{tabular}{ccc}
\hline Organism & Concentration of tryptophan $(\mathrm{g} / \mathrm{L})$ & Absorbance \\
\hline & 0.05 & 0.105 \\
& 0.12 & 0.047 \\
$\mathbb{I N}_{1} 2 \mathrm{a}$ & 0.18 & 0.03 \\
& 0.22 & -0.015 \\
& 0.25 & -0.014 \\
\hline & 0.05 & 0.423 \\
$\mathrm{M}_{1} 2 \mathrm{a}$ & 0.12 & 0.190 \\
& 0.18 & -0.007 \\
& 0.22 & -0.012 \\
& 0.25 & -0.02 \\
\hline
\end{tabular}

Tested isolates $\left(\mathrm{IN}_{1} 2 \mathrm{a}\right.$ and $\left.\mathrm{M}_{1} 2 \mathrm{a}\right)$ could not produce ammonia after addition of reagent. Both the Isolates $\mathrm{M}_{1} 2 \mathrm{a}$ and $\mathrm{IN}_{1} 2 \mathrm{a}$ were able solubilize phosphate in Pikovskaya's agar (Figure 1).

Isolates $\mathrm{IN}_{1} 2 \mathrm{a}$ and $\mathrm{M}_{1} 2 \mathrm{a}$ were able to ferment sugars like glucose, fructose, lactose, sucrose, galactose, mannose, mannitol, maltose and xylose. Based on the sugar assimilation pattern, test isolates could be B. subtilis, B. licheniformis, B. pumilus, B. brevis, $B$. stearothermophilus.

Table 4: Sugars assimilation pattern of isolates

\begin{tabular}{|c|c|c|c|}
\hline Organism & Sugars & Result & Possible organisms \\
\hline \multirow{9}{*}{$\mathrm{IN}_{1} 2 \mathrm{a}$} & Glucose & Positive & Bacillus subtilis \\
\hline & Fructose & Positive & Bacillus licheniformis \\
\hline & Lactose & Positive & Bacillus pumilus \\
\hline & Sucrose & Positive & Bacillus brevis \\
\hline & Galactose & Positive & Bacillus stearothermophilus \\
\hline & Mannose & Positive & \\
\hline & Mannitol & Positive & \\
\hline & Maltose & Positive & \\
\hline & Xylose & Positive & \\
\hline \multirow{9}{*}{$M_{1} 2 a$} & Glucose & Positive & Bacillus subtilis \\
\hline & Fructose & Positive & Bacillus licheniformis \\
\hline & Lactose & Positive & Bacillus pumilus \\
\hline & Sucrose & Positive & Bacillus brevis \\
\hline & Galactose & Positive & Bacillus stearothermophilus \\
\hline & Mannose & Positive & \\
\hline & Mannitol & Positive & \\
\hline & Maltose & Positive & \\
\hline & Xylose & Positive & \\
\hline
\end{tabular}

As describe in Table 5, only isolate M12a was able to

tolerate the sodium arsenite up to $1500 \mathrm{ppm}$. 
Table 5: Growth of isolates on different concerntration of sodium arsenite containing NA media after incubation at $37^{\circ} \mathrm{C}, 48$ hours

\begin{tabular}{|c|c|c|}
\hline Isolates & $\begin{array}{l}\text { Concentration of Sodium arsenite } \\
(\mathrm{ppm})\end{array}$ & Absorbance $(\lambda=610 \mathrm{~nm})$ \\
\hline \multirow[t]{7}{*}{$M_{1} 2 a$} & 0 & 1.723 \\
\hline & 200 & 1.649 \\
\hline & 400 & 1.140 \\
\hline & 600 & 1.323 \\
\hline & 800 & 0.923 \\
\hline & 1000 & 0.351 \\
\hline & 1500 & 0.124 \\
\hline \multirow[t]{4}{*}{$\mathrm{IN}_{1} 2 \mathrm{a}$} & 0 & 1.213 \\
\hline & 200 & 1.132 \\
\hline & 400 & 0.762 \\
\hline & 600 & 0.000 \\
\hline
\end{tabular}

16Sr RNA gene sequence analysis result indicated that the isolate $\mathrm{M}_{1} 2 \mathrm{a}$ showed $99.2 \%$ similarity with Bacillus flexus. The phylogenetic analysis clearly showed the isolate grouped to Bacillus species (Figure 2).

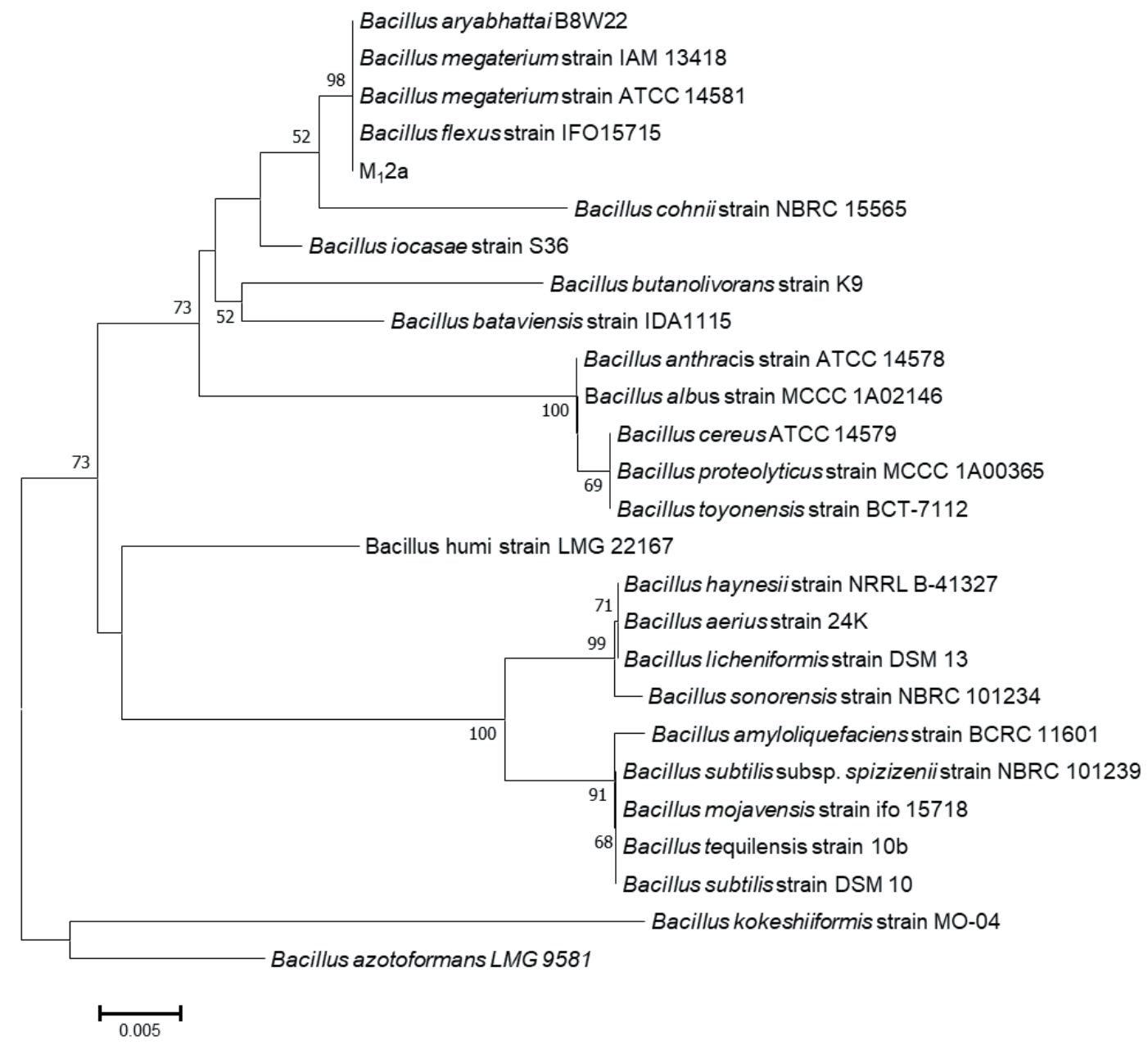

Figure 2: Neighbor-joining phylogenetic tree of isolate $M_{1} 2 a$ and other closely related reference strains based on $16 \mathrm{~S}$ rRNA gene sequences. 
The growth $\mathrm{pH}$ of the isolate $\mathrm{M}_{1} 2 \mathrm{a}$ and $\mathrm{IN}_{1} 2 \mathrm{a}$ ranged from 5.0 - 9.0. The optimum $\mathrm{pH}$ for the growth of isolate $\mathrm{M}_{1} 2 \mathrm{a}$ and $\mathrm{IN}_{1} 2 \mathrm{a}$ was 7.0. Similarly, the optimum
$\mathrm{NaCl}$ concentration for the growth of isolate $\mathrm{M}_{1} 2 \mathrm{a}$ and $\mathrm{IN}_{1} 2 \mathrm{a}$ was $2 \%$ (Figure 3 ).
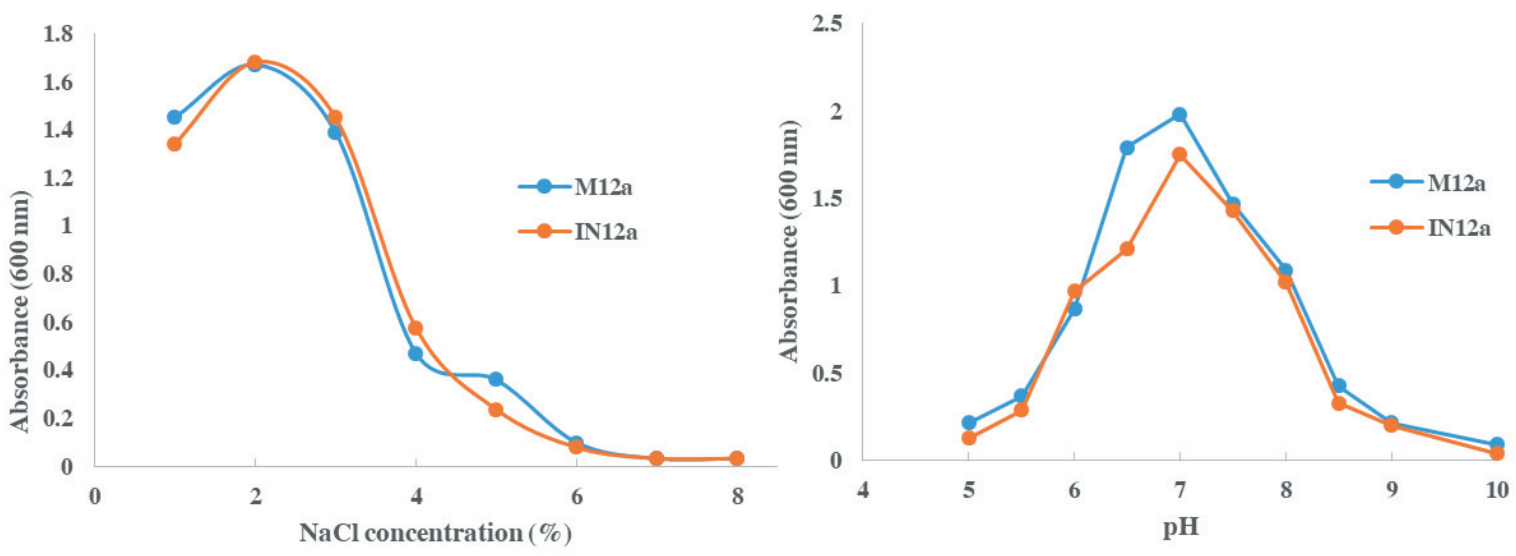

Figure 3: Growth of arsenic resistant isolates on different $\mathrm{pH}$ values and $\mathrm{NaCl}$ concentrations

\section{DISCUSSION}

From the results it can be observed that the $\mathrm{pH}$ of the soil was slightly acidic which is suitable for the growth of the most of plants (Kumar et al. 2019). In addition, some useful microorganisms can tolerate acidic $\mathrm{pH}$ and are applicable for crop enhancement (Kumar et al. 2019). Soil is the largest deposit of heavy metals such as arsenic and their compounds. These compounds may be harmful to other components of soil such as animals and plants. However, a solution to this problem can also be found in soil in the form of microorganisms that can utilize and degrade these harmful metals. Mostly the soil inhabitant microbes such as Bacillus species have been reported by many researchers (Schallmey et al. 2004; Radhakrishnan et al. 2017). In this study, Gram positive, endospore forming rod-shaped bacteria was isolated and tentatively identified as genus Bacillus. Travers et al. (1987) have reported the isolation of Bacillus species from various soil samples.

Isolation of arsenic resistance Bacillus species have been reported previously (Satyapal et al. 2016; Shakya et al. 2012; Selvi et al. 2014; Dey et al. 2016). Arsenic resistance Bacillus aryabhattai was isolated from the Indian soil and water samples (Singh et al. 2016). In this study, forty-two isolates were found to be Gram positive spore forming rod shaped bacteria. Shakya et al. (2011) also reported techniques of identification of Bacillus spp. based on cultural, morphological, and biochemical characteristics. On screening of these isolates for arsenic tolerance, 3 isolates produced colonies on Nutrient agar. The resistance was determined by inoculating the isolates on NA supplemented with sodium arsenite (Selvi et al. 2014). Colony formation in NA indicated the tolerance of arsenite and could possibly determine the toxic arsenite is utilized and converted to non-toxic forms. Only the arsenic tolerance isolates were vertically streaked on arsenic-supplemented NA and incubated. After incubation, the plates were flooded with freshly prepared silver nitrate solution which cause formation of yellowish brown precipitate which is suggestive of metabolic activity on the arsenite in the medium. This test confirmed the utilization of arsenic by the isolates $\mathrm{IN}_{1} 2 \mathrm{a}$ and $\mathrm{M}_{1} 2 \mathrm{a}$. Selvi et al. (2014) also reported similar precipitation seen in media plates supplemented by arsenic and flooded with $\mathrm{AgNO}_{3}$.

The arsenic resistance isolates were then tested for plant growth promoting activities. Indole acetic acid production was measured highest when the concentration of tryptophan was $0.05 \%$. At higher concentration of tryptophan, there was low accumulation of IAA. This might be due to inhibitory effect of tryptophan against growth of Bacillus species. Ahmad et al. (2005) reported a contradictory result where IAA production increased with the increase in concentration of tryptophan in the medium when inoculated with Psuedomonas and Azotobacter isolates. The difference in results may be due to difference in type of microbes and their sensitivities to differing compounds. None of the isolates tested were capable of producing ammonia, both isolates were able to 
solubilize phosphate in the medium. As a result, a clear zone of hydrolysis was observed around the fully developed colonies of isolates $\mathrm{IN}_{1} 2 \mathrm{a}$ and $\mathrm{M}_{1} 2 \mathrm{a}$ when grown on Pikovskaya's agar (Figure 1). According to Kitpreechavanich et al. (2016) Bacillus spp. have the ability to produce a clear zone around their colonies on Pikovskaya's agar by solubilizing phosphate in the medium.

Arsenic resistance isolates $\mathrm{IN}_{1} 2 \mathrm{a}$ and $\mathrm{M}_{1} 2 \mathrm{a}$ were able to assimilate all of the sugars tested. Bacillus spp. are well characterized and are able to assimilate the sugars as shown in Table 4. According to Bergey's manual of determinative bacteriology (1957) probably the isolates could be B. subtilis, B. licheniformis, B. pumilus, B. brevis, Geobacillus stearothermophilus.

Isolates $\mathrm{M}_{1} 2 \mathrm{a}$ tolerated up to $1000 \mathrm{ppm}$ of sodium arsenite and 15000 ppm sodium arsenate, which is the highest reported in Nepalese soil. In addition, mild growth was observed even up to 1500 ppm of sodium arsenite. However, further studies are necessary in this regard. The isolates showed growth from acidic to alkaline $\mathrm{pH}$ and at high concentration of $\mathrm{NaCl}$, which is a typical characteristics of many Bacillus species (Poudel et al. 2016). Based on the 16S rRNA gene sequencing, high resistance isolate M12a was identified as Bacillus flexus. To our knowledge, this is the first report of isolation of arsenic resistant and plant growth promoting Bacillus flexus in Nepalese soil. These tests provide evidence that the isolates $\mathrm{IN}_{1} 2 \mathrm{a}$ and $\mathrm{M}_{1} 2 \mathrm{a}$ could be useful for the preparation of effective biofertilizer having PGP activity and bioremediation behavior. However, further testing is required to determine more characteristics of the isolates and also their best possible use in bioremediation of arsenic.

\section{CONCLUSION}

This is the first report to show the isolation of arsenic resistant and plant growth promoting Bacillus flexus in Nepalese soil. The result indicated that the isolates could be useful for the preparation of effective biofertilizer having PGP activity and bioremediation behavior. However, other experiments on arsenic resistant genes are necessary at the molecular level to understand the whole mechanism.

\section{ACKNOWLEDGEMENTS}

The research grant provided by UGC (Award No. SRDIG/74-75/S\&T-2) and TWAS (Award No. 18-131 RG/BIO/AS_I-FR3240303645) supported to conduct this research work.

\section{CONFLICT OF INTEREST}

The authors declare no conflict of interest.

\section{REFERENCES}

Ahmad F, Ahmad I and Khan MS (2005). Indole acetic acid production by the indigenous isolates of Azotobacter and fluorescent Pseudomonas in the presence and absence of tryptophan. Turkish Journal of Biology 29(1): 29-34.

Banerjee M, Banerjee N, Bhattacharjee P, Mondal D, Lythgoe PR, Martínez M, Pan J, Polya DA and Giri AK (2013). High arsenic in rice is associated with elevated genotoxic effects in humans. Scientific Reports 22;3: 2195.

Bergey DH, Breed RS, Murray EGD and Hitchens AP (1957). Bergey's manual of determinative bacteriology (pp. 122-414). Baltimore: Williams \& Wilkins.

Dey U, Chatterjee S and Kumar N (2016). Isolation and characterization of arsenic-resistant bacteria and possible application in bioremediation. Biotechnol Rep 10: 1-7.

Ghosh P, Rathinasabapathi B and Ma LQ (2011). Arsenic-resistant bacteria solubilized arsenic in the growth media and increased growth of arsenic hyperaccumulator Pteris vittata L Bioresour technol 102(19): 8756-8761.

Kitpreechavanich V, Hayami A, Talek A, Chin CFS, Tashiro Y and Sakai K (2016). Simultaneous production of L-lactic acid with high optical activity and a soil amendment with food waste that demonstrates plant growth promoting activity. J Biosc Bioeng 122(1): 105-110

Kumar A, Kumari M, Swarupa P and Shireen (2019). Characterization of $\mathrm{pH}$ Dependent Growth Response of Agriculturally Important Microbes for Development of Plant Growth Promoting Bacterial Consortium, J Pure Appl Microbiol 13(2): 1053-1061.

Loper JE, Haack C and Schroth MN (1985). Population dynamics of soil pseudomonads in the rhizosphere of potato (Solanum tuberosum L.). Appl Environ Microbiol 49(2): 416-422.

Mallick I, Hossain ST, Sinha S and Mukherjee SK (2014). Brevibacillus sp. KUMAs2, a bacterial isolate for 
possible bioremediation of arsenic in rhizosphere. Ecotoxicol Environ Safety 107: 236-244.

Pepi M, Volterrani M, Renzi M, Marvasi M, Gasperini S, Franchi E and Focardi SE (2007). Arsenicresistant bacteria isolated from contaminated sediments of the Orbetello Lagoon, Italy, and their characterization. J Appl Microbio 103(6): 2299-2308.

Poudel P, Tashiro Y and Sakai K (2016). New application of Bacillus strains for optically pure L-lactic acid production: general overview and future prospects. Biosc Biotechnol Biochem 80(4): 642-654.

Radhakrishnan R, Hashem A and Abd_Allah EF (2017). Bacillus: a biological tool for crop improvement through bio-molecular changes in adverse environments. Front Physiol 6: 8:667

Satyapal GK, Rani S, Kumar M and Kumar N (2016). Potential Role of Arsenic Resistant Bacteria in Bioremediation: Current Status and Future Prospects. J Microb Biochem Technol 8: 256-258.

Schallmey M, Singh A and Ward OP (2004). Developments in the use of Bacillus species for industrial production. Canadian Journal of Microbiology 50(1): 1-17

Selvi MS, Sasikumar S, Gomathi S, Rajkumar P,
Sasikumar P and Govindan S (2014). Isolation and characterization of arsenic resistant bacteria from agricultural soil, and their potential for arsenic bioremediation. Int J Agric Policy Res 2: 393-405.

Shagol CC, Krishnamoorthy R, Kim K, Sundaram S and Sa T (2014). Arsenic-tolerant plant-growthpromoting bacteria isolated from arsenic-polluted soils in South Korea. Environ Sci Pollut Res 21(15): 9356-9365.

Shakya S, Pradhan B, Smith L, Shrestha J and Tuladhar $S$ (2012). Isolation and characterization of aerobic culturable arsenic-resistant bacteria from surface water and groundwater of Rautahat District, Nepal. J Envion Manage 95: S250-S255.

Singh N, Gupta S, Marwa N, Pandey V, Verma PC, Rathaur S and Singh N (2016). Arsenic mediated modifications in Bacillus aryabhattai and their biotechnological applications for arsenic bioremediation. Chemosphere 164: 524-534.

Smith E, Kempson I, Juhasz AL, Weber J, Skinner WM and Gräfe M (2009). Localization and speciation of arsenic and trace elements in rice tissues. Chemosphere 76(4): 529-535.

Travers RS, Martin PA and Reichelderfer CF (1987). Selective Process for Efficient Isolation of Soil Bacillus spp. Appl Environ Microbiol 53(6): 12631266. 